\title{
Pemetaan Topografi Calon Lokasi Embung di Kampus IPB Dramaga, Bogor
}

\section{(Topographic Mapping of Prospective Small Dam Location in IPB Campus} Dramaga, Bogor)

\begin{abstract}
Bagus Rahmansyah Priyoadi ${ }^{1 *}$ dan Budi Indra Setiawan ${ }^{1}$
${ }^{1}$ Departemen Teknik Sipil dan Lingkungan, Fakultas Teknologi Pertanian, Institut Pertanian Bogor. Kampus IPB Dramaga, PO BOX 220, Bogor, Jawa Barat Indonesia

*Penulis korespondensi: bagusrahmansyah93@yahoo.com

Diterima: 11 September 2019

Disetujui: 23 Desember 2019

ABSTRACT

Before planning and designing a small dam, land's topographic mapping and water flow pattern's analysis are needed. The aim of this research were to identify the land use, water catchment areas, water flow pattern, and analyze land's topographic condition, as well as producing topographic maps and calculating inundation volume at small dam location at IPB Campus Dramaga. This research was conducted in April - July 2019. The land use around the small dam location consisted of forests, roads, grasslands, bare land, settlements, and agriculture lands. The catchment area of the small dam location was divided into four area, with an area of $2881.0 \mathrm{~m}^{2}, 4531.0 \mathrm{~m}^{2}, 2790.0 \mathrm{~m}^{2}$, and $10917.3 \mathrm{~m}^{2}$ respectively. The highest and lowest elevations at small dam location were 199.71 masl and 187.23 masl. The topographic map was created using Surfer 13 software with the most appropriate interpolation method was natural neighbor. The direction of the surface water flow was relatively uniform and leads to the North and South. The minimum and maximum of inundation volume were $1.5 \mathrm{~m}^{3}$ and $13752.8 \mathrm{~m}^{3}$, and the optimum inundation volume was $2824.8 \mathrm{~m}^{3}$.
\end{abstract}

Keywords: land use, small dam, flow patterns, topographic map, inundation volume

\section{PENDAHULUAN}

Institut Pertanian Bogor (IPB) merupakan salah satu perguruan tinggi negeri yang ada di Indonesia. Menurut Soekarno dalam Nabilah et al. (2017), IPB memiliki fasilitas pendukung kegiatan kampus untuk menunjang kegiatan pendidikan dan penelitian, yaitu adanya University Farm (UF IPB) yang meliputi kebun percobaan, kolam, laboratorium laut, ladang penggembalaan ternak, dan hutan pendidikan. IPB memiliki beberapa kampus, salah satunya adalah Kampus Dramaga yang berada di Kecamatan Dramaga, Kabupaten Bogor.

Sumber air utama yang digunakan untuk memenuhi kebutuhan air di Kampus IPB Dramaga berasal dari dua sungai besar, yaitu Sungai Ciapus dan Cihideung. Saat hujan lebat, Sungai Ciapus dan Cihideung sering meluap, sehingga menyebabkan distribusi air baku utama di Kampus IPB Dramaga terganggu. Sumber air alternatif diperlukan untuk memenuhi kebutuhan air di Kampus IPB Dramaga.

Air hujan dan limpasan permukaan dapat ditampung dan dimanfaatkan sebagai sumber air alternatif. Penampungan air hujan bermanfaat untuk mengantisipasi kekeringan di musim kemarau serta mengatasi masalah genangan dan limpasan permukaan di musim hujan (Angraini 2018). Salah satu kegiatan yang dapat dilakukan untuk mengatasi permasalahan tersebut adalah membuat embung (Aprizal 2015). 
Sebelum merencanakan dan merancang embung, perlu dilakukan pemetaan topografi lahan dan analisis pola aliran air untuk menentukan lokasi embung yang strategis di Kampus IPB Dramaga, Bogor. Salah satu lokasi yang cukup potensial untuk dibangun embung adalah di sekitar kandang ternak Fakultas Peternakan IPB. Tujuan dari penelitian ini untuk mengidentifikasi penggunaan lahan, daerah tangkapan air, pola aliran air, dan menganalisis kondisi topografi lahan, serta menghasilkan peta topografi dan menghitung volume genangan di bendungan kecil yang terletak di Kampus IPB Dramaga.

\section{METODOLOGI}

Penelitian ini dilakukan pada bulan April hingga Juli 2019. Penelitian berlokasi di sekitar kandang ternak Fakultas Peternakan, Kampus IPB Dramaga, Bogor. Lokasi penelitian disajikan pada Gambar 1.

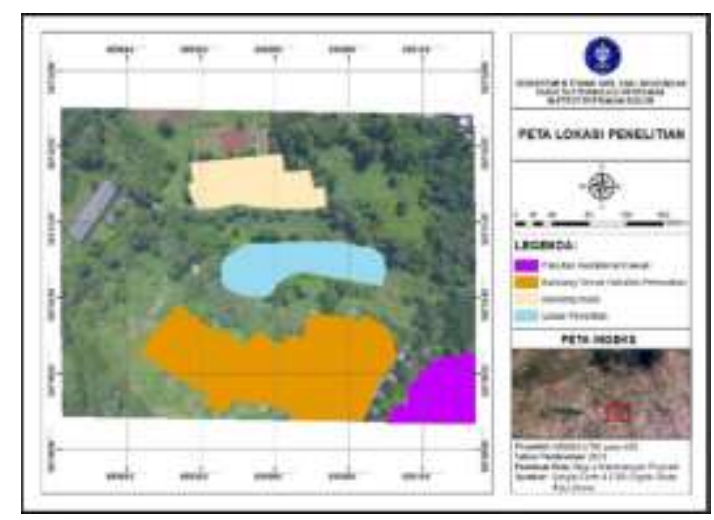

Gambar 1. Peta lokasi penelitian

Alat yang digunakan dalam penelitian ini adalah pita ukur, Global Positioning System (GPS), target rod, patok, theodolite digital, alat tulis, drone, serta komputer yang dilengkapi dengan perangkat lunak Microsoft Excel 2016, Google Earth, ArcGIS 10.4.1, dan Surfer 13.

Bahan yang digunakan dalam penelitian ini berupa data primer dan data sekunder. Data primer berupa data topografi lahan, titik koordinat, serta foto udara yang diambil secara langsung di lapangan menggunakan drone. Data sekunder yang digunakan berupa citra satelit dari lokasi penelitian yang diperoleh melalui Google Earth.

Data topografi lahan diperoleh dari pengukuran menggunakan metode grid. Tahapan pertama yang dilakukan adalah menentukan batas area pengukuran dan membuat kotak-kotak grid dengan menggunakan pita ukur dan patok. Jarak setiap kotak grid ditentukan sebesar $2 \mathrm{~m}$.

Titik set-up awal yang ditentukan juga digunakan sebagai titik acuan (benchmark) bagi titik-titik dalam grid. Terbatasnya jangkauan alat yang hanya dapat mencapai jarak maksimum sekitar $200 \mathrm{~m}$ menyebabkan titik set-up alat harus berpindah-pindah lokasinya.

Pembacaan dan pencatatan nilai hasil pengukuran pada setiap titik mencakup nilai benang atas, tengah, dan bawah yang dapat dibaca dengan jelas, serta sudut horizontal dan vertikal yang mengacu ke arah utara. Data-data yang diperoleh dari hasil pembacaan alat tersebut dapat menunjukkan jarak, elevasi, serta lokasi dari setiap titik yang mengacu pada titik set-up alat ketika nilai dari setiap titik dibaca. Titik set-up awal yang juga digunakan sebagai benchmark, diukur koordinat dan elevasinya dengan menggunakan GPS.

Data hasil pengukuran dan pemetaan topografi lahan yang diperoleh dimasukkan ke perangkat lunak Microsoft Excel 2016 untuk dilakukan perhitungan jarak dan elevasi dari setiap titik detil dalam grid, dengan mengacu pada titik benchmark. Menurut Afifie (2015), jarak horizontal dapat dihitung menggunakan persamaan (1).

$d=(B A-B B) \times 10 \times(\cos \theta)$

Keterangan:

$\mathrm{BA}=$ nilai benang atas terbaca 
$\mathrm{BB}=$ nilai benang bawah terbaca

$\theta \quad=$ sudut vertikal

Hasil perhitungan berupa nilai jarak kemudian dapat digunakan untuk menentukan koordinat lintang (x) dan bujur (y) dari setiap titik, dengan menggunakan titik benchmark sebagai acuan. Koordinat $\mathrm{x}$ dan y dari setiap titik mengacu pada koordinat titik benchmark. Koordinat titik benchmark yang digunakan dalam perhitungan dikonversi terlebih dahulu ke dalam satuan Universal Transverse Mercator (UTM). Menurut Marzuki et al. (2000), koordinat x dan y setiap titik dapat dihitung dengan menggunakan persamaan (2) hingga (5).

$$
\begin{aligned}
& \Delta X=d x(\sin \alpha) \\
& \Delta Y=d x(\cos \alpha) \\
& X 1=X o+\Delta X \ldots \\
& Y 1=Y o+\Delta Y \ldots
\end{aligned}
$$

Keterangan:

$\Delta \mathrm{X} \quad=$ perbedaan nilai koordinat $\mathrm{x}$ suatu titik dengan titik sebelumnya (m)

$\Delta \mathrm{Y} \quad=$ perbedaan nilai koordinat y suatu titik dengan titik sebelumnya (m)

$\mathrm{Xo}=$ koordinat $\mathrm{x}$ titik benchmark $(\mathrm{m})$

Yo = koordinat $\mathrm{y}$ titik benchmark $(\mathrm{m})$

$\mathrm{X} 1=$ koordinat $\mathrm{X}$ suatu titik $(\mathrm{m})$

$\mathrm{Y} 1=$ koordinat $\mathrm{y}$ suatu titik $(\mathrm{m})$

$\mathrm{d}=$ jarak horizontal $(\mathrm{m})$

$\alpha \quad=$ sudut horizontal

Elevasi merupakan posisi vertikal (ketinggian) suatu objek terhadap titik tertentu (datum). Umumnya, datum yang digunakan mengacu pada tinggi permukaan air laut yang sering dinyatakan sebagai ketinggian di atas permukaan laut (dpl). Datum mengacu pada titik benchmark, yang elevasinya sudah ditentukan dengan menggunakan GPS. Menurut Afifie (2015), beda elevasi dan elevasi (z) untuk setiap titik yang diukur dapat dihitung dengan menggunakan persamaan (6) dan (7).
$\Delta Z=1 / 2 x((B A-B B) x \sin 2 \theta+T A-B T) . .(6)$
$Z=Z o+\Delta Z \ldots \ldots \ldots \ldots \ldots \ldots \ldots \ldots \ldots \ldots \ldots \ldots \ldots \ldots \ldots \ldots$

Keterangan:

$\mathrm{BA}=$ nilai benang atas terbaca

$\mathrm{BB}=$ nilai benang bawah terbaca

$\theta \quad=$ sudut vertikal

Apabila penyebaran data sangat besar terhadap nilai rata-rata, maka nilai standar deviasi atau simpangan baku (Sx) akan besar, dan sebaliknya. Menurut Soewarno dalam Yusniyanti dan Kurniati (2017), nilai $\mathrm{Sx}$ dapat dihitung dengan menggunakan persamaan (8).

$S x=\sqrt{\frac{\sum_{1-n}^{n}(X i-X r a t a)^{2}}{n-1}}$.

Keterangan:

$\mathrm{Xi}=$ nilai varian

Xrata $=$ rata-rata hitung

$\mathrm{n} \quad=$ jumlah data

Data koordinat x dan y, serta elevasi dari setiap titik pengukuran yang telah diperoleh dari pengolahan data primer selanjutnya dapat digunakan untuk membuat peta topografi. Peta topografi yang dihasilkan dapat menunjukkan perbedaan elevasi lahan berdasarkan titiktitik pengukuran, sehingga dapat dilakukan analisis pola aliran air permukaan yang ada di lokasi embung.

Pembuatan peta topografi dan pola aliran air permukaan dilakukan dengan menggunakan bantuan perangkat lunak Surfer 13. Metode interpolasi yang digunakan untuk membuat peta topografi lokasi embung pada Surfer 13 adalah metode Inverse Distance to a Power (IDP), kriging, dan natural neighbor.

Setelah membuat peta topografi dari lokasi embung, selanjutnya dapat dilakukan analisis potensi volume genangan pada lokasi embung. Nilai potensi volume genangan dihitung berdasarkan perbedaan elevasi dalam peta 
topografi. Menurut Soewarno dalam Ulfa et al. (2017), volume genangan berdasarkan topografinya dapat dihitung menggunakan persamaan (9).

$V=\frac{1}{3} \times D \times\left(A_{n}+A_{(n+1)}+\sqrt{A_{n} \times A_{(n+1)}}\right.$

Keterangan:

$\mathrm{V} \quad=$ volume $\left(\mathrm{m}^{3}\right)$

$\mathrm{D} \quad=$ jarak antara dua potongan melintang (m)

An = luas potongan melintang $\mathrm{An}\left(\mathrm{m}^{2}\right)$

$\mathrm{A}(\mathrm{n}+1)=$ luas potongan melintang $\mathrm{A}(\mathrm{n}+1)$ $\left(\mathrm{m}^{2}\right)$

\section{HASIL DAN PEMBAHASAN}

\section{Kondisi Tata Guna Lahan dan Daerah Tangkapan Air}

Tata guna lahan di lokasi embung terbagi dalam beberapa jenis tutupan lahan dan digambarkan dalam bentuk peta. Peta tata guna lahan lokasi embung dibuat dengan menggunakan perangkat lunak ArcGIS 10.4.1. Peta tata guna lahan lokasi embung dapat dilihat pada Gambar 2. Berdasarkan peta tata guna lahan pada Gambar 2, lokasi embung terbagi atas enam jenis tutupan lahan. Tutupan lahan tersebut di antaranya adalah hutan, jalan, lahan kosong, padang rumput, pemukiman, dan pertanian. Sebagian besar tutupan lahan pada lokasi embung didominasi oleh hutan dan padang rumput.

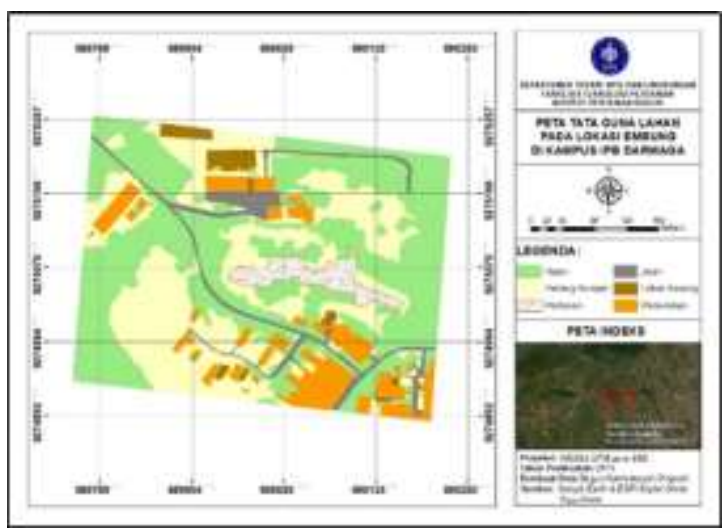

Gambar 2. Peta tata guna lahan

Daerah tangkapan air (DTA) merupakan tempat terjadinya proses pengalih ragaman hujan menjadi aliran permukaan pada suatu kawasan (Purboseno et al. 2013). Peta pembagian DTA pada lokasi embung beserta luasnya dapat dilihat pada Gambar 3 dan Tabel 1. DTA 4 memiliki area yang paling luas. Luas tiap DTA dihitung berdasarkan tata guna lahan yang ada pada Gambar 3 .

Berdasarkan Tabel 1 luas total DTA

$1,2,3$, dan 4 masing-masing adalah 2881.0 $\mathrm{m}^{2}, \quad 4531.0 \mathrm{~m}^{2}, 2790.0 \mathrm{~m}^{2}$, dan 10917.3 $\mathrm{m}^{2}$. Jenis tata guna lahan pada DTA 4 terdiri dari hutan, padang rumput, lahan kosong, pemukiman, dan jalan, dengan luas masing-masing sebesar $5687.6 \mathrm{~m}^{2}$, $2969.6 \mathrm{~m}^{2}, 239.5 \mathrm{~m}^{2}, 1865.1 \mathrm{~m}^{2}$, serta $155.6 \mathrm{~m}^{2}$.

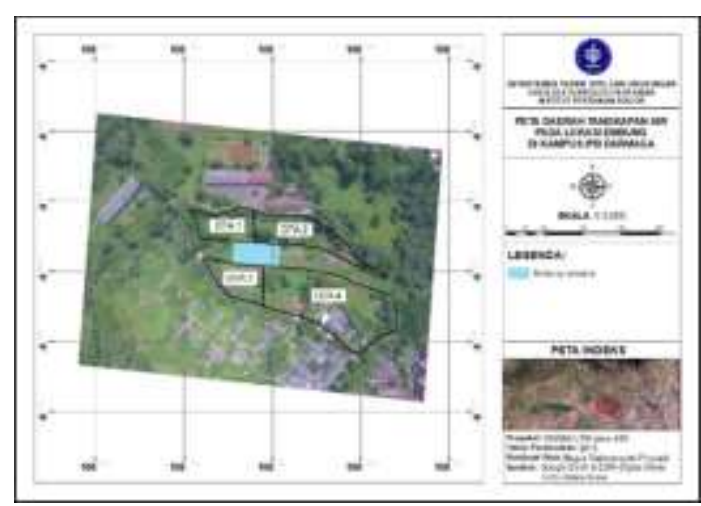

Gambar 3. Peta pembagian DTA pada lokasi embung

Tabel 1 Luas DTA pada lokasi embung

\begin{tabular}{|c|c|c|c|}
\hline DTA & $\begin{array}{c}\text { Jenis tata guna } \\
\text { lahan }\end{array}$ & Luas $\left(m^{2}\right)$ & $\begin{array}{c}\text { Luas total } \\
\left(\mathrm{m}^{2}\right)\end{array}$ \\
\hline \multirow[t]{2}{*}{1} & Hutan & 1758.8 & 2881.0 \\
\hline & Padang rumpat & 11222 & \\
\hline \multirow{3}{*}{2} & Hutan & 21049 & \\
\hline & Padang rumput & 2087.0 & 4531.0 \\
\hline & Sawah & 339.18 & \\
\hline \multirow{3}{*}{3} & Hutan & 1436.8 & \\
\hline & Padang rumpat & 875.9 & 2790.0 \\
\hline & Sawah & 477.3 & \\
\hline \multirow{5}{*}{4} & Hutan & 5687.6 & \\
\hline & Padang rumput & 2969.6 & \\
\hline & Lahan kosong & 239.5 & 10917.3 \\
\hline & Pemukiman & 1865.1 & \\
\hline & Jalan & 155.6 & \\
\hline \multirow[t]{2}{*}{5} & Hutan & 1758.8 & 2881.0 \\
\hline & Padang rumpat & 11222 & \\
\hline \multirow{3}{*}{6} & Hutan & 21049 & \\
\hline & Padang rumpat & 2087.0 & 4531.0 \\
\hline & Sawah & 339.18 & \\
\hline \multirow{3}{*}{7} & Hetan & 1436.8 & \\
\hline & Padang rumpat & 875.9 & 2790.0 \\
\hline & Sawah & 477.3 & \\
\hline \multirow{5}{*}{8} & Hutan & 5687.6 & \\
\hline & Padang rumput & 2969.6 & \\
\hline & Lahan kosong & 239.5 & 10917.3 \\
\hline & Pemukiman & 1865.1 & \\
\hline & Jalan & 155.6 & \\
\hline
\end{tabular}




\section{Pemetaan Topografi Lokasi Embung}

Pemetaan topografi lokasi embung dilakukan dengan menggunakan theodolite digital merk Topcon DT-205L, dengan tingkat ketelitian sebesar lima detik. Pengukuran titik-titik detail dilakukan dengan menggunakan metode grid. Metode grid akan membuat titik-titik pengukuran satu dengan yang lainnya saling mengikat (Marzuki et al. 2000). Jarak antar patok dan jalur dalam grid dibuat sebesar $2 \mathrm{~m}$.

Ilustrasi pengukuran topografi dengan metode grid yang dilakukan pada penelitian ini ditunjukkan pada Gambar 4. Titik-titik detail dilakukan, sudut theodolite digital harus dinolkan ke arah utara terlebih dahulu. Titik ikat yang digunakan dalam pengukuran topografi ini mengacu pada titik benchmark (BM) berupa patok kayu. Koordinat titik BM terletak pada $106.72^{\circ} \mathrm{BT}$ dan $6.56^{\circ} \mathrm{LS}$, dengan elevasi $197 \mathrm{mdpl}$.

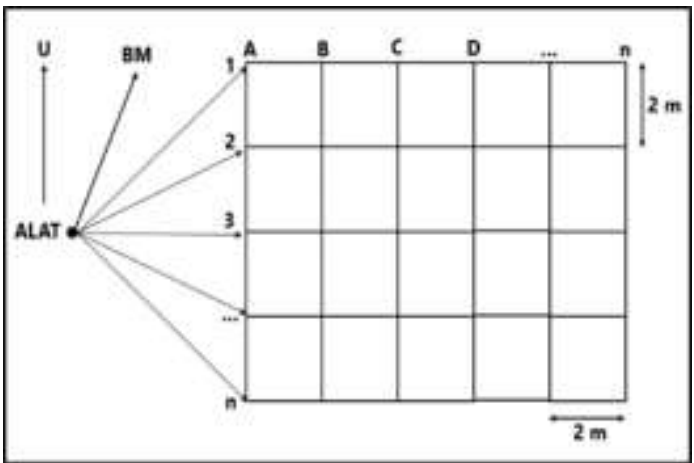

Gambar 4. Pengukuran metode grid

Pengukuran titik BM dilakukan menggunakan alat GPS tipe Garmin, dengan nilai error terukur sebesar $\pm 5 \mathrm{~m}$. Luas area pemetaan topografi embung sebesar $4197.2 \mathrm{~m}^{2}$, dengan jumlah titik pengukuran sebanyak 702 titik. Batas area pemetaan topografi lokasi embung yang dilakukan ditunjukkan pada Gambar 5.

Data hasil pengukuran topografi lokasi embung yang diperoleh diolah menggunakan perangkat lunak Microsoft Excel 2016. Hasil pengolahan data pengukuran topografi lahan berupa data koordinat bujur (x) dan lintang (y), serta elevasi (z) dari setiap titik pengukuran dalam grid yang dipetakan.

Berdasarkan hasil perhitungan, elevasi tertinggi dari lokasi embung adalah 199.71 mdpl dan elevasi terendahnya adalah $187.23 \mathrm{mdpl}$. Standar deviasi atau simpangan baku dari data hasil perhitungan elevasi adalah sebesar $\pm 2.87 \mathrm{~m}$. Data koordinat $\mathrm{x}, \mathrm{y}$, dan $\mathrm{z}$ tersebut kemudian dikonversi ke dalam satuan UTM dan disimpan dalam format .csv, untuk diolah menjadi peta topografi dengan menggunakan perangkat lunak Surfer 13.

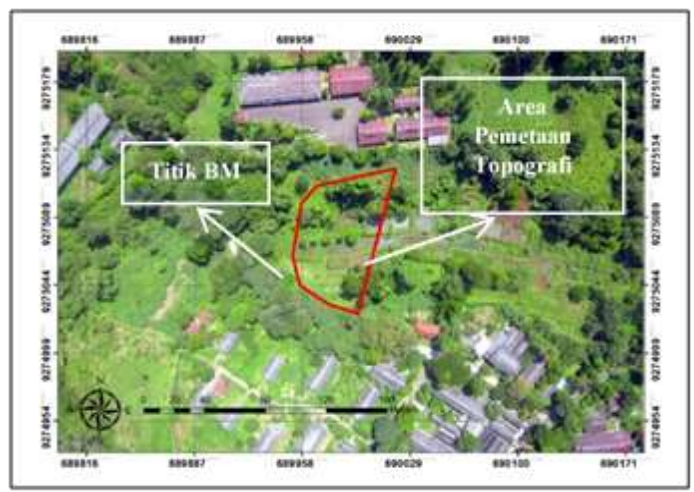

Gambar 5. Batas area pemetaan topografi

Pembuatan peta topografi pada Surfer 13 menggunakan tiga metode interpolasi, yaitu metode Inverse Distance to a Power (IDP), kriging, dan natural neighbor. Metode IDP, kriging, dan natural neighbor merupakan beberapa metode yang sering digunakan untuk menginterpolasi data koordinat dan elevasi dari hasil pengukuran lahan.

Menurut Keckler dalam Siregar dan Selamat (2009), metode IDP adalah interpolator dalam pembuatan peta kontur yang menggunakan pembobotan jarak dari titik. Nilai suatu titik yang diinterpolasi dengan menggunakan metode ini sangat dipengaruhi oleh titik-titik lain yang lebih dekat dengan titik tersebut.

Metode kriging adalah interpolator geostatistik yang sering digunakan pada berbagai bidang ilmu, terutama pada pertambangan. Metode ini dapat 
menghubungkan titik-titik bernilai ekstrem tanpa mengisolasinya. Menurut van Beers dan Kleijnen dalam Siregar dan Selamat (2009), hasil interpolasi metode kriging lebih akurat dibandingkan metode regresi. Pada metode kriging, semakin dekat nilai masukan yang digunakan, maka korelasi keluaran dengan masukan akan semakin kuat.

Metode natural neighbor merupakan metode interpolasi yang bersifat lokal, yaitu hanya menggunakan masukan yang berada di sekitar titik yang akan diinterpolasi. Menurut Pasaribu dan Haryani dalam Afifie (2015), hasil yang diperoleh dari metode interpolasi natural neighbor akan sama dengan elevasi titik sampel yang digunakan sebagai masukan dalam proses interpolasi.

Interval kontur yang digunakan dalam proses interpolasi adalah $1 \mathrm{~m}$. Skala warna merah menunjukkan elevasi tertinggi sedangkan skala warna biru menunjukkan elevasi terendah. Peta topografi hasil interpolasi metode natural neighbor menggunakan perangkat lunak Surfer 13 dapat dilihat pada Gambar 6.

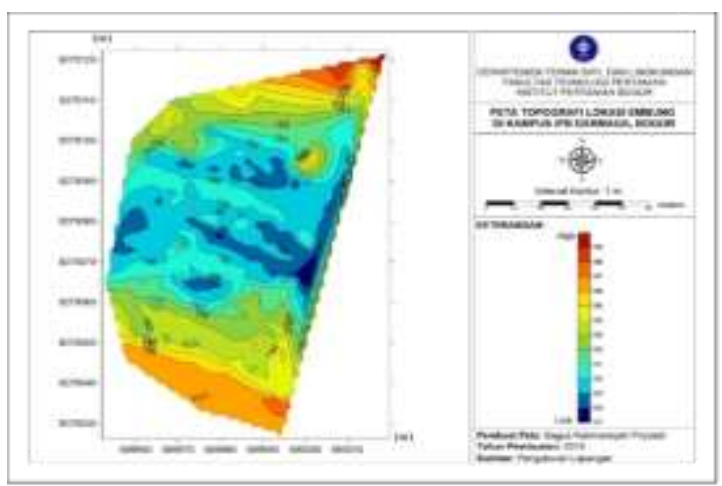

Gambar 6. Peta topografi lokasi embung interpolasi metode natural neighbor

Berdasarkan peta topografi yang telah dibuat, metode natural neighbor memberikan hasil interpolasi paling mendekati hasil pengukuran topografi lokasi embung di lapangan. Elevasi tertinggi dan terendah dari peta topografi hasil interpolasi metode ini masing-masing adalah sebesar $199.5 \mathrm{mdpl}$ dan $187.0 \mathrm{mdpl}$.

\section{Pola Aliran Air}

Peta pola aliran air dapat dibuat menggunakan perangkat lunak Surfer 13 berdasarkan peta topografi. Pola aliran air yang terbentuk akan menggambarkan aliran air berupa limpasan permukaan yang mengalir dan terkonsterasi pada suatu titik mengikuti bentuk topografi lahan. Peta pola aliran air pada lokasi embung dapat dilihat pada Gambar 7, yang menunjukkan aliran air permukaan yang terjadi saat musim hujan relatif seragam. Sebagian besar air permukaan akan mengalir ke arah Utara dan Selatan lahan, menuju titik dengan elevasi terendah yang terletak di bagian tengah dari lokasi embung.

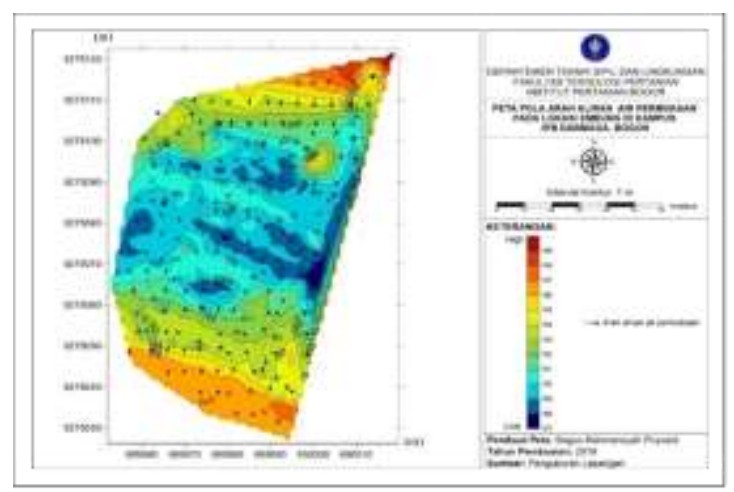

Gambar 7. Peta pola aliran air

\section{Potensi Volume Genangan}

Nilai potensi volume genangan pada lokasi embung dapat dihitung berdasarkan perbedaan elevasi pada topografi eksisting. Perbedaan nilai elevasi dapat diketahui dari peta topografi yang telah dibuat dengan menggunakan perangkat lunak Surfer 13. Perhitungan potensi volume genangan dilakukan untuk elevasi 187-195 mdpl, pada kedalaman 0-8 m. Hasil perhitungan potensi volume genangan dapat dilihat pada Tabel 2 .

Berdasarkan data pada Tabel 2, volume genangan kumulatif minimum pada kedalaman $0.5 \mathrm{~m}$ adalah sebesar 1.5 $\mathrm{m}^{3}$. Volume genangan kumulatif maksimum pada kedalaman $8 \mathrm{~m}$ adalah sebesar $13752.8 \mathrm{~m}^{3}$. 
Tabel 2 Potensi volume genangan

\begin{tabular}{cccc}
\hline $\begin{array}{c}\text { Kedalaman } \\
(\mathrm{m})\end{array}$ & $\begin{array}{c}\text { Luas } \\
\left(\mathrm{m}^{2}\right)\end{array}$ & $\begin{array}{c}\text { Volume } \\
\left(\mathrm{m}^{3}\right)\end{array}$ & $\begin{array}{c}\text { Volume } \\
\text { kumulatif }\left(\mathrm{m}^{3}\right)\end{array}$ \\
\hline 0.0 & 0.0 & 0.0 & 0.0 \\
0.5 & 9.0 & 1.5 & 1.5 \\
1.0 & 39.8 & 11.3 & 12.8 \\
1.5 & 113.6 & 36.8 & 49.6 \\
2.0 & 586.9 & 159.8 & 209.4 \\
2.5 & 917.0 & 372.9 & 582.3 \\
3.0 & 1258.5 & 541.6 & 1123.9 \\
3.5 & 1801.5 & 761.0 & 1884.9 \\
4.0 & 1959.0 & 939.9 & 2824.8 \\
4.5 & 2104.5 & 1015.7 & 3840.5 \\
5.0 & 2255.2 & 1089.7 & 4930.2 \\
5.5 & 2576.8 & 1207.1 & 6137.3 \\
6.0 & 2773.5 & 1337.3 & 7474.6 \\
6.5 & 2978.3 & 1437.6 & 8912.2 \\
7.0 & 3122.9 & 1525.2 & 10437.4 \\
7.5 & 3349.1 & 1617.7 & 12055.1 \\
8.0 & 3441.9 & 1697.7 & 13752.8 \\
\hline
\end{tabular}

Menurut Setiawan et al. (2016), kedalaman embung berkisar antara 2-4 m. Volume genangan optimum pada lokasi embung adalah pada kedalaman $4 \mathrm{~m}$, yaitu sebesar $2824.8 \mathrm{~m}^{3}$.

Hubungan antara kedalaman (y) dengan luas (L) dan volume genangan kumulatif (V) berbanding lurus. Hubungan antara kedalaman dengan luas dan volume pada lokasi embung ditunjukkan dalam bentuk grafik pada Gambar 8 .

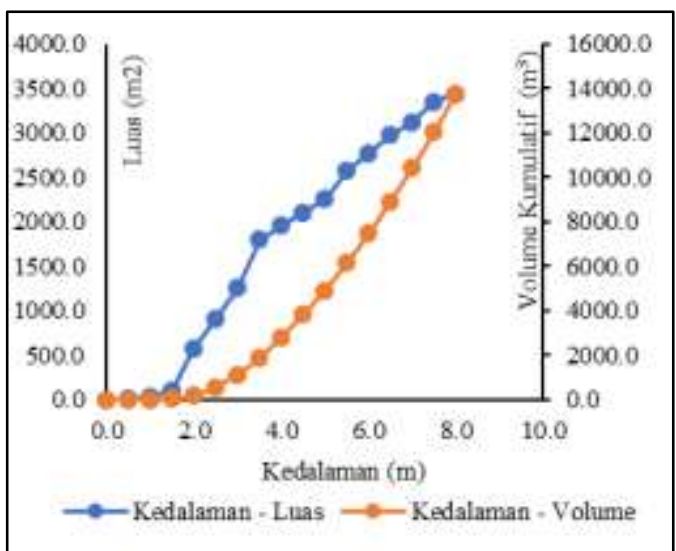

Gambar 8. Hubungan antara kedalaman dengan luas dan volume genangan

\section{KESIMPULAN}

Kesimpulan yang dapat diambil adalah:

1. Tata guna lahan di sekitar calon lokasi embung terbagi menjadi enam jenis tutupan lahan, yaitu hutan, jalan, padang rumput, lahan kosong, pemukiman, serta pertanian, dan terdapat 4 DTA pada lokasi embung dengan luas masing-masing sebesar $2881.0 \mathrm{~m}^{2}, 4531.0 \mathrm{~m}^{2}, 2790.0 \mathrm{~m}^{2}$, dan $10917.3 \mathrm{~m}^{2}$

2. Kondisi topografi lokasi embung memiliki elevasi tertinggi $199.71 \mathrm{mdpl}$ dan elevasi terendahnya adalah $187.23 \mathrm{mdpl}$, dan peta topografi yang dihasilkan dibuat menggunakan perangkat lunak Surfer 13 dengan metode interpolasi yang paling sesuai adalah natural neighbor.

3. Pola aliran air pada lokasi embung relatif seragam dan sebagian besar mengalir ke arah Utara dan Selatan lahan, menuju titik dengan elevasi terendah yang terletak di bagian tengah lokasi embung.

4. Volume genangan kumulatif minimum pada kedalaman $0.5 \mathrm{~m}$ sebesar $1.5 \mathrm{~m}^{3}$ dan volume genangan kumulatif maksimum pada kedalaman $8 \mathrm{~m}$ sebesar $13752.8 \mathrm{~m}^{3}$, serta volume genangan optimum sebesar $2824.8 \mathrm{~m}^{3}$ pada kedalaman $4 \mathrm{~m}$.

\section{DAFTAR PUSTAKA}

Afifie AF. 2015. Pemetaan topografi dan rancangan perataan lahan di Balai Besar Penelitian Tanaman Padi (Subang, Jawa Barat) [skripsi]. Bogor (ID): Institut Pertanian Bogor.

Angraini L. 2018. Perencanaan desain embung di Sentul City [skripsi]. Bogor (ID): Institut Pertanian Bogor.

Aprizal. 2015. Perencanaan Embung Tejomartani Desa Branti Raya Natar, Lampung Selatan. Jurnal Teknik Sipil UBL. 6(1):696-714.

Marzuki A, Widito P, Sularto P. 2000. Pengukuran Topografi Daerah Mineralisasi Uranium Sektor Jumbang I Kalimantan Barat. Prosiding Seminar Pranata Nuklir dan Teknisi Litkayasa; Jakarta (ID): P2BGN-BATAN. hlm 43-56.

Nabilah R, Mugnisjah WQ, Gunawan A. 2017. Model lanskap permakultura Kebun Percobaan Cikabayan untuk memenuhi kebutuhan pangan bergizi 
mahasiswa asrama IPB. Jurnal Lanskap Indonesia. 9(1):120-126.

Purboseno S, Bambang AN, Suripin, Hadi SP. 2013. Evaluasi Karakteristik Daerah Tangkapan Air sebagai Acuan Kegiatan Konservasi Sumber Daya Air. Prosiding Seminar Nasional Pengelolaan Sumberdaya Alam dan Lingkungan. Semarang (ID): Program Studi Ilmu Lingkungan Pascasarjana Universitas Diponegoro. hlm 226231.

Setiawan BI, Wirasembada YC, Kuswanda WP, Jannati SL, Andayani A. 2016. Penentuan Lokasi, Rancangan, dan Pembuatan Embung untuk Pertanian; Upaya Menghadirkan Solusi Permanen Mengatasi Kritis Kekeringan. Bogor (ID): Balai Besar Penelitian dan Pengembangan Sumberdaya Lahan Pertanian, Badan Penelitian dan Pengembangan Pertanian.

Siregar VP, Selamat MB. 2009. Interpolator dalam pembuatan kontur peta batimetri. E-Jurnal Ilmu dan Teknologi Kelautan Tropis. 1(1):3947.

Ulfa A, Suprayogi S, Khoirullah EM. 2017. Perhitungan kapasitas Waduk Ngancar Batuwarno, Wonogiri, Jawa Tengah. Media Komunikasi Geografi. 18(2):156-165.

Yusniyanti E, Kurniati. 2017. Analisa puncak banjir dengan metode MAF (studi kasus Sungai Krueng Keureuto). Jurnal Einstein 5(1):712 